\title{
An Optimal Investment Scheduling Framework for Intelligent Transportation Systems Architecture
}

\author{
FARAMAK ZANDI ${ }^{1}$ and MADJID TAVANA ${ }^{2}$ \\ ${ }^{1}$ Information Systems, Faculty of Technology and Engineering, Alzahra University, Vanak, Tehran, Iran \\ ${ }^{2}$ Management Information Systems, La Salle University, Philadelphia, Pennsylvania, USA
}

\begin{abstract}
Transportation planning in general, and planning for intelligent transportation systems (ITSs) in particular, are notable for multiple goals and for multiple constituencies. A review of the current literature offers several ITS investment evaluation methods that provide frameworks for the quantification of risks and benefits. Nevertheless, the traditional selection methods overemphasize quantitative and economic analysis and often neglect to consider qualitative and noneconomic data in the formal selection process. Furthermore, crisp data are fundamentally indispensable in traditional ITS investment selection methods. However, the data in real-world problems are often imprecise or ambiguous. In this article, we propose a novel fuzzy group multi-criteria framework for ITS investment evaluation and selection that takes into consideration (1) the qualitative and quantitative criteria and their respective value judgments; (2) the verbal expressions and linguistic variables for qualitative judgments which lead to ambiguity in the decision process; and (3) imprecise or vague judgments. First, we use fuzzy TOPSIS to calculate the fuzzy risk values with each ITS architecture subsystem. Next, we use fuzzy ROA to calculate the fuzzy real option values of the ITS subsystems. Last, we determine the optimal investment schedule for the ITS subsystems by considering the risk and option values as the coefficients of the objective functions in a group multi-objective decision-making model.
\end{abstract}

Keywords Intelligent Transportation System Architecture; Multi-Criteria Decision Analysis; Fuzzy Real Option Analysis; Group Multi-Objective Decision Making

\section{INTRODUCTION}

Over the past decade, the importance of and reliance on systems architectures has grown substantially because of the increasing complexity in information- and computer-based systems. The systems architecture is a framework that guides and moderates the evolution of many interrelated elements in a complex system and provides order and rules so that hardware, software, data, and communications can work in harmony. An intelligent transportation system (ITS) applies advanced technologies such as electronics, communication, information, image processing, and various sensors to catch real-time information that helps not only to improve transportation safety,

The authors thank the managing editor, Professor Hong Lo, for his insightful comments and suggestions.

Address correspondence to Madjid Tavana, Management Information Systems, La Salle University, Philadelphia, PA 19141, USA. E-mail: tavana@ lasalle.edu mobility, and productivity, but also to reduce transportation impacts on the environment (Shaheen and Finson, 2004).

The rapid advances in technology have created many new opportunities for transportation agencies to deliver safer and more efficient transportation services. However, many of these new opportunities are based on effective coordination among different public and private agencies. To encourage this coordination, the U.S. Department of Transportation (2009) developed the National ITS Architecture to help identify and exploit these opportunities for cost-effective cooperation. The national ITS architecture has a total of 21 subsystems with interconnections depicted in Figure 1.

The ITS architecture describes interaction among physical components of the transportation systems including control centers, travelers, vehicles, and roadside devices. The control center subsystems provide management, administrative, and support functions for the transportation system. The traveler subsystems include services that are owned and operated by 


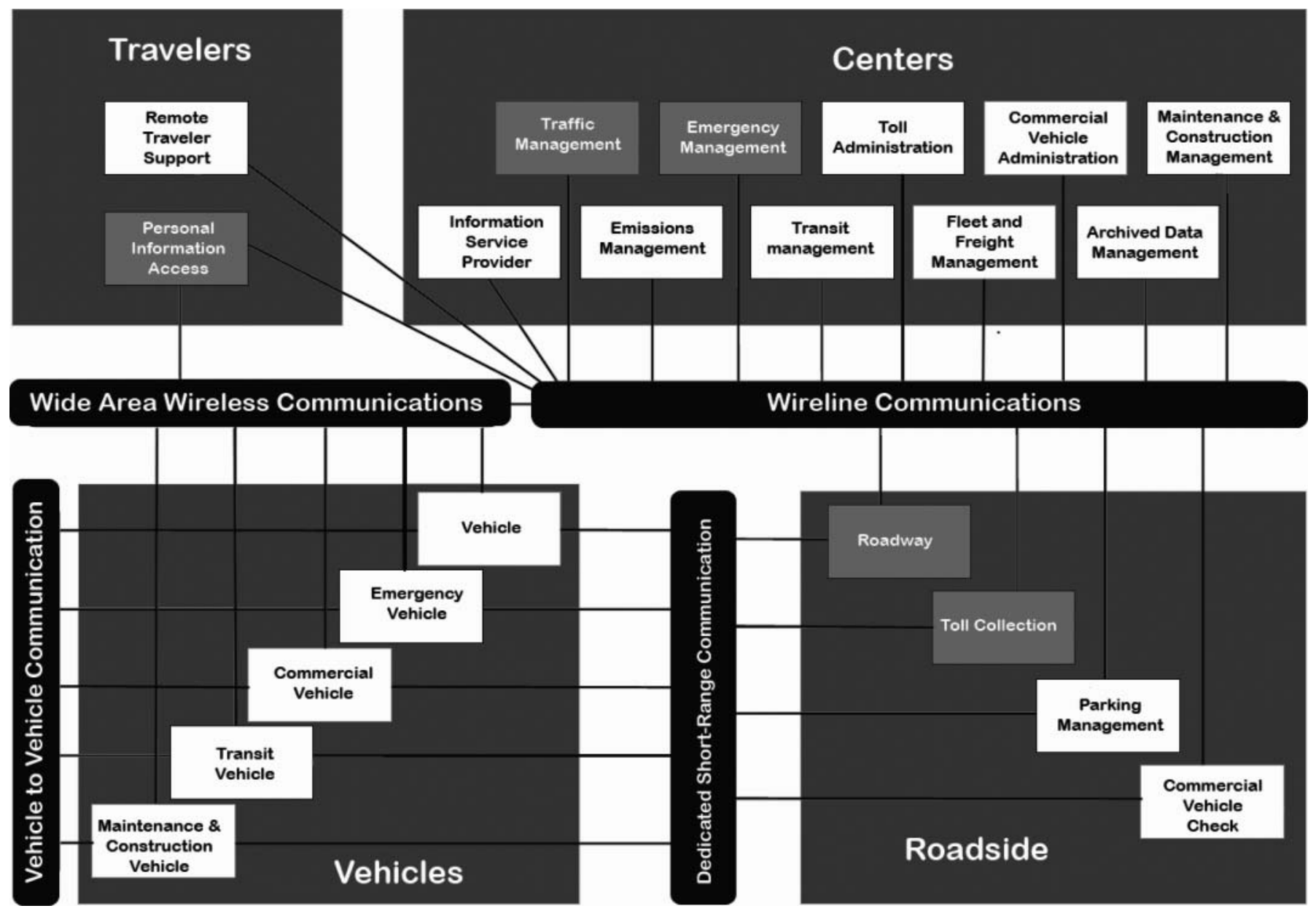

Figure 1 The high-level architecture diagram for the intelligent transportation system subsystems. Source: U.S. Department of Transportation (2009).

the traveler as well as services that are owned by transportation and information providers. The vehicle subsystems cover ITS-related elements on vehicle platforms and include general driver information and safety systems applicable to all vehicle types. The roadside subsystems include an intelligent infrastructure distributed along the transportation network that perform surveillance, information provision, and plan execution control functions.

In recent years, the development of regional ITS architectures are of increasing importance as ITS technologies are becoming increasingly affordable. A regional ITS architecture guides the development of ITS investment in the regions, and many researchers have studied alternative evaluation methods for these investment (Hodota, 2006). Bristow, Pearman, and Shires (1997) critically assessed procedures that have been adopted to evaluate ITS projects and concluded that appropriate ITS evaluation methods have not yet been established. McConnell (2005) analyzed various characteristics of ITS services and applied the concepts of ROA to ITS.

Although the developments in ITS have been largely hardware driven and have led to the introduction of many sophisti- cated technologies in the transportation arena, the development of evaluation models for investment in ITS technology are lagging behind (Crainic, Gendreau, and Potvin, 2009). In addition, the increasing complexity in the transportation system and the larger number of conflicting criteria has made the ITS investment selection and planning a difficult and complex task posing significant challenges (Thill, Rogova, and Yan, 2004). Crainic et al. (2009) argued that further research in operations research and decision sciences are needed for ITS to reach its full potential.

A review of the current literature offers several ITS investment evaluation methods that provide frameworks for the quantification of risks and benefits. Cost-benefit analysis is the most widely used method to assess the risks and benefits associated with the ITS investments strategies (De Corla-Souza, Everett, Gardner, and Culp, 1997; Gillen and Levinson, 2004). The costbenefit analysis methods deal with two problems: (a) the difficulty of quantifying the value of indirect benefits and (b) the difficulty of identifying intangible benefits or costs (Leviakangas, 1998; Schniederjans et al., 2004). Although, cost-benefit analysis is useful where the costs and benefits are intangible, 
the method requires the existence of a broad agreement on the measures used to evaluate the intangibles. Haynes and Li (2004) have shown that the traditional cost-benefit analysis may not effectively address value-added, system perspective, and various uncertainties involved in the ITS development and deployment. They proposed two extensions of cost-benefit analysis. The first extension internalizes positive externalities of ITS through productivity gain, and the second extension incorporates system consideration by disaggregating direct gains from ITS into timesaving, increased interaction and increased land-use activities.

In addition to the aforementioned traditional quantitative approaches, there is a stream of research studies that emphasizes real options analysis. Real options analysis differs from traditional methods in terms of priceability of the underlying investment strategy (McGrath, 1997). With traditional methods, the underlying investment strategy of an option is priced as known (Black and Scholes, 1973), while in information technology investment situations the price of an underlying investment is rarely known (McGrath, 1997). The real options analysis uses three basic types of data: (a) current and possible future investment options, (b) the desired capabilities sought by the organization, and (c) the relative risks and costs of other ITS investment strategies that could be used. The method can help assess the risks associated with the ITS investment strategies by taking into consideration the changing nature of the business strategies and organizational requirements (Leviakangas and Lahesmaa, 2002).

Real options are commonly valued with the Black-Scholes option pricing formula (Black and Scholes, 1973, 1974), the binomial option valuation method (Cox, Ross, and Rubinstein, 1979) and Monte Carlo methods (Boyle, 1977). These methods assume that the underlying markets can be imitated accurately as a process. Although this assumption may hold for some efficiently traded financial securities, it may not hold for real ITS investments that do not have existing markets (Collan, Fuller, and Mezei, 2009). Recently, a simple novel approach to real options analysis called the Datar-Mathews method (Datar and Mathews, 2004, 2007; Mathews and Salmon, 2007) was proposed wherein the real option value is calculated from a payoff distribution, derived from a probability distribution of the net present value for an investment strategy generated with a Monte Carlo simulation. This approach does suffer from the market process assumptions associated with the Black-Scholes method (Black and Scholes, 1974).

In general, there are three types of real options: growth, postponement, and abandonment options (Scarso, 1996). Growth options include scaling up an investment and give the opportunity to exploit a prior investment in a sequential investment. Postponement options involve deferring an investment in order to obtain new information. Abandonment options include scaling down an investment and allow managers to exit from an investment. Postponement and growth options are considered most important by managers and the abandonment option is considered less important (Busby and Pitts, 1997). This typology is not exactly the same as the option pricing model, which focuses on deferring decision making in order to obtain a larger expected value than a now-or-never type investment (Benaroch and Kauffman, 1999). De Neufvil (2003) argued that the integration of real options analysis will radically revolutionize the design of public and private systems by changing the processes of system design and the way planners deal with uncertainty and risk.

Transportation planning in general, and planning for ITS in particular, are notable both for multiple goals and for multiple constituencies. Multi-criteria decision analysis (MCDA) plays a pivotal role in the evaluation and selection of alternative ITS investment and communication strategies (Levine and Underwood, 1996; Ma, Zhou, Chowdhury, Wang, and Fries, 2009). The ITS investment evaluation and selection problems embrace qualitative and quantitative criteria. Nevertheless, the traditional selection methods overemphasize quantitative and economic analysis and often neglect to consider qualitative and non-economic data in the formal selection process. When facing such MCDA problems, the literature and research show that the following difficulties may be encountered in the decision process:

1. Decision makers often use verbal expressions and linguistic variables for qualitative judgments which lead to ambiguity in the decision process (Poyhonen, Hamalainen, and Salo, 1997).

2. Decision makers often provide imprecise or vague information as a result of lack of expertise or unavailability of data (Kim and Ahn, 1999).

3. Meaningful and robust aggregation of qualitative and quantitative data causes difficulties in the decision process (Valls and Torra, 2000).

4. A decision process is not complete without fully taking into consideration all the criteria and their respective value judgments (Belton and Stewart, 2002; Yang and Xu, 2002).

The MCDA methods have also been successfully applied in various ITS decision problems. Iniestra and Gutiérrez (2009) proposed a framework to solve a transportation infrastructure investment selection problem using a constrained multiobjective optimization model with quadratic objective functions. Macharis, Verbeke, and De Brucker (2004) developed a strategic evaluation methodology building upon the analytic hierarchy process and MCDA to assess advanced driver assistance systems by synthesizing information from stakeholder analyses and technical performance studies in ITS. De Brucker, Verbeke, and Macharis (2004) discussed the applicability of MCDA to the evaluation of ITS using the analytic hierarchy process and the Preference Ranking Organization Method for Enrichment Evaluations (PROMETHEE). They critically examined the strengths and weaknesses of MCDA as compared with cost-benefit analysis, especially in the context of ITS applications.

Management of uncertainty is an intrinsically important issue in ITS investment scheduling decisions. Uncertainty is dealt with through fuzzy logic and probabilistic logic in the existing MCDA literature. Fuzzy logic and probabilistic logic 
are mathematically similar but conceptually distinct. Fuzzy logic corresponds to degrees of truth, whereas probabilistic logic corresponds to likelihood. A feature of fuzzy logic that is of particular importance to the management of uncertainty is that it provides a systematic framework for dealing with fuzzy quantifiers within a single conceptual framework (Zadeh, 1983).

Fuzzy logic and fuzzy sets can represent ambiguous, uncertain or imprecise information in real options analysis and MCDA by formalizing inaccuracy in human decision making (Collan et al., 2009). For example, fuzzy sets allow for graduation of belonging in future cash-flow estimation (i.e., future cash flow at Year 7 is about 7 million dollars). Fuzzy set algebra developed by Zadeh (1965) is the formal body of theory that allows the treatment of imprecise estimates in uncertain environments.

The choice between fuzzy logic and probabilistic logic is not easy. For infinite spaces, the disadvantage is with the probabilities that have very high computational cost. For finite spaces, probabilities give higher flexibility at the cost of higher computational complexity. Oversimplifying a probabilistic model so that its computations can be easily performed may reduce the information conveyed to such a level that fuzzy models would be preferable for their simplicity, efficiency and information content (Drakopoulos, 1995). In this study, we use fuzzy logic because of their lower computational complexity and information content.

In recent years, several researchers have combined fuzzy set theory with ITS research. Quek, Pasquier, and Lim (2009) studied ITS and developed a self-organizing fuzzy rule-based system for modeling traffic flow. Wang, Lin, and Chen (2010) proposed a new lane-detection and lane-departure warning system on the basis of fuzzy rules. Traditional ITS assessment techniques overemphasize quantitative and economic analysis and often neglect to consider qualitative and noneconomic factors in the formal selection process. Furthermore, crisp data are fundamentally indispensable in traditional ITS investment selection methods. However, the data in real-world problems are often imprecise or ambiguous. The prior research in ITS investment selection does not embrace qualitative and quantitative criteria exhibiting imprecise and ambiguous value judgments. The technique for order preference by similarity to ideal solution (TOPSIS) is a well-known method proposed by Hwang and Yoon (1981) to consider both qualitative and quantitative criteria in MCDA. TOPSIS originates from the theory of the displaced ideal in which the ranking of the alternatives is based on the shortest distance from the positive ideal solution and the farthest from the negative ideal solution (Zeleny, 1974). Kim, Park, and Yoon (1997) and Shih, Shyur, and Lee (2006) have shown that TOPSIS is based on the following: (a) a sound logic that represents the rationale of human choice, (b) a unique visualization of the alternatives on a polyhedron, (c) a scalar value that accounts for the best and worst alternative choices simultaneously, and (d) a simple computation process that can be easily programmed into a spreadsheet.
In this article, we propose a novel fuzzy group multi-criteria framework for ITS investment evaluation and selection that takes into consideration (a) the qualitative and quantitative criteria and their respective value judgments, (b) the verbal expressions and linguistic variables for qualitative judgments that lead to ambiguity in the decision process, and (c) imprecise or vague judgments. First, we use fuzzy TOPSIS to calculate the fuzzy risk values with each ITS architecture subsystem. Next, we use fuzzy ROA to calculate the fuzzy real option values of the ITS subsystems. Last, we determine the optimal investment schedule for the ITS subsystems by considering the risk and option values as the coefficients of the objective functions in a group multi-objective decision-making model.

As a simple example, let us consider the following five ITS architecture subsystems for investment in a 4-year planning horizon: the Traffic Management Subsystem, the Roadway Subsystem, the Emergency Management Subsystem, the Toll Administration Subsystem, and the Parking Management Subsystem. Using the proposed method, these five subsystems could be scheduled based on the investments risks and the real option criteria as follows: the Emergency Management Subsystem and the Traffic Management Subsystem will be deployed during the first year, whereas the Roadway Subsystem, the Toll Administration Subsystem, and the Parking Management Subsystem will be deployed in the second, third, and fourth year, respectively.

\section{The Mathematical Notations}

Let us introduce the following mathematical notations and definitions used throughout this article:

$\tilde{A}$

$\tilde{A}^{K}$

The weighted fuzzy collective matrix of $n$ subsystems with respect to $p$ ITS investment risk criteria

$=$ The fuzzy individual matrix of $n$ subsystems with respect to $p$ ITS investment risk criteria evaluated by the ITS investment board member $(\text { ITSIB })_{k}$

$\tilde{a}_{i j} \quad=$ The fuzzy ordinal rank of the $i$ th ITS architecture subsystem with respect to the $j$ th criterion

$\tilde{a}_{i j}^{k} \quad=$ The fuzzy ordinal rank of the $i$ th ITS architecture subsystem with respect to the $j$ th criterion evaluated by the ITS investment board member $(\text { ITSIB })_{k}$

$\underline{V}_{R} \quad=$ The normalized relative closeness vector

$\bar{G}_{i} \quad=$ The relative closeness of the $i$ th ITS architecture subsystem with respect to $S_{i}^{*}$

$=$ The ideal ITS architecture subsystem

$=$ The nadir ITS architecture subsystem

$=$ The separation between the $i$ th ITS architecture subsystem with the ideal ITS architecture subsystem $(i=1,2, \ldots, n)$

$=$ The separation between the $i$ th ITS architecture subsystem with the nadir ITS

$=$ The number of ITS investment board members 


\begin{tabular}{|c|c|}
\hline$c l_{i}$ & $=$ The $i$ th class of ITS architecture \\
\hline$h$ & $=$ The number of ITS architecture classes \\
\hline$s_{i}$ & $=$ The $i$ th subsystem of ITS architecture \\
\hline$n$ & $=$ The number of ITS architecture subsystems \\
\hline$x_{j}$ & $=$ The $j$ th investment risk criterion \\
\hline$p$ & $=$ The number of investment risk criteria \\
\hline$w_{j}$ & $\begin{aligned}= & \text { The importance weight of the } j \text { th investment } \\
& \text { risk criterion }\end{aligned}$ \\
\hline$w(D M)_{K}$ & $\begin{aligned}= & \text { The voting power of the ITS investment board } \\
& \text { member }(\text { ITSIB })_{k} ;(K=1,2, \ldots, l)\end{aligned}$ \\
\hline$R_{F R O V}$ & $\begin{aligned}= & \text { The real option value matrix of the ITS archi- } \\
& \text { tecture subsystems }\end{aligned}$ \\
\hline
\end{tabular}

$F R O V_{i}\left(T_{j}\right)=$ The fuzzy real option value of the $i$ th ITS subsystem at time $T_{j}$

$F R V_{i} \quad=$ The fuzzy risk value of the $i$ th ITS subsystem

$\tilde{B}_{i}\left(T_{j}\right) \quad=$ The weighted collective fuzzy present value of the expected cash flows of the $i$ th ITS subsystem at time $T_{j}$

$\tilde{C}_{i}\left(T_{j}\right) \quad=$ The weighted collective fuzzy present value of the expected cost of the $i$ th ITS subsystem at time $T_{j}$

$\tilde{B}_{i}^{k}\left(T_{j}\right) \quad=$ The individual fuzzy present value of the expected cash flows of the $i$ th ITS subsystem at time $T_{j}$ evaluated by the ITS investment board member $(I T S I B)_{k}$

$\tilde{C}_{i}^{k}\left(T_{j}\right) \quad=$ The individual fuzzy present value of the expected cost of the $i$ th ITS subsystem at time $T_{j}$ evaluated by the ITS investment board member $(I T S I B)_{k}$

$E\left(\tilde{B}_{i}\left(T_{j}\right)\right)=$ The possibilistic mean value of the weighted collective present value of expected cash flows of the $i$ th ITS subsystem at time $T_{j}$

$E\left(\tilde{C}_{i}\left(T_{j}\right)\right)=$ The possibilistic mean value of the weighted collective expected costs of the $i$ th ITS subsystem at time $T_{j}$

$\left(\sigma^{2}\left(T_{j}\right)\right)_{i}=$ The variance of the weighted collective fuzzy present value of the expected cash flows of the $i$ th ITS subsystem at time $T_{j}$ evaluated by the ITS investment board member $(I T S I B)_{k}$

$\delta_{i} \quad=$ The value loss over the duration of the option

$r_{i} \quad=$ The risk-free interest rate

$N\left(D_{1 i}\left(T_{j}\right)\right)=$ The cumulative normal probability $D_{1}$ for the $i$ th ITS subsystem

$N\left(D_{2 i}\left(T_{j}\right)\right)=$ The cumulative normal probability $D_{2}$ for the $i$ th ITS subsystem

$T_{m} \quad=$ The maximum deferral time of the ITS investments

$T_{1} \quad=$ The minimum deferral time of the ITS investments

\section{THE PROPOSED FRAMEWORK}

The modular model depicted in Figure 2 is proposed to evaluate and plan the ITS subsystems:

\section{Phase 1: The Establishment of the ITS Investment Board}

In this phase, we establish an ITS investment board. Let us assume that $l$ ITS investment board members are selected to participate in the planning process:

$$
\begin{aligned}
& \frac{I T S I B}{} \\
& \quad=\left[(I T S I B)_{1},(I T S I B)_{2}, \ldots,(I T S I B)_{k}, \ldots,(I T S I B)_{l}\right]
\end{aligned}
$$

The proposed framework in this study allows for assigning the following voting power weights to each ITS board member:

$\underline{W}(D M)=\left[w(D M)_{1}, w(D M)_{2}, \ldots, w(D M)_{j}, \ldots, w(D M)_{l}\right]$

This vector of voting power weights is calculated by the ITS board using the eigenvector of the following pairwise comparison matrix:

$$
\begin{gathered}
(I T S I B)_{1} \\
(I T S I B)_{2} \\
\vdots \\
(I T S I B)_{l}
\end{gathered}\left[\begin{array}{cccc}
(I T S I B)_{1} & (\text { ITSIB })_{2} & \cdots & (\text { ITSIB })_{l} \\
- & \frac{v_{1}}{v_{2}} & \cdots & \frac{v_{1}}{v_{l}} \\
\vdots & \vdots & \cdots & \frac{v_{2}}{v_{l}} \\
\frac{v_{l}}{v_{1}} & \frac{v_{l}}{v_{2}} & \cdots & \vdots
\end{array}\right]
$$

\section{Phase 2: The Calculation of the Fuzzy Risk Values of the ITS Architecture Subsystems}

In this phase, we use fuzzy group TOPSIS to calculate the fuzzy risk values. This phase is divided into the following six steps:

\section{Step 2.1: The Identification of the ITS Architecture Subsystems Requirement}

In this step, the ITS investment board defines the boundaries of the national/regional ITS architecture. In addition, the board identifies a set of ITS architecture subsystem requirements. The ITS deployment always takes place on a regional scale consistent with the national ITS architecture (Sussman, 2005, p. 153). This consistency is intended to facilitate the goal of national efficiency and interoperability. The history of the republic has been shaped by the tension between strong central government and the prerogatives of the states. This idea of efficiency at the regional and national level is just another manifestation of this tension (Sussman, 2005, p. 155). Let us consider the following classes and ITS architecture subsystems with the maximum deferral time $T_{m}$ :

$$
\begin{aligned}
\underline{C L} & =\left[c l_{1}, c l_{2}, \ldots, c l_{h}\right] \\
\underline{S} & =\left[S_{1}, S_{2}, \ldots, S_{n}\right]
\end{aligned}
$$

vol. 15 no. 32011 
Phase 1: The establishment of the ITS investment board

Phase 2: The calculation of the fuzzy risk values of the ITS architecture subsystems

Step 2.1: The identification of the ITS architecture subsystem requirements

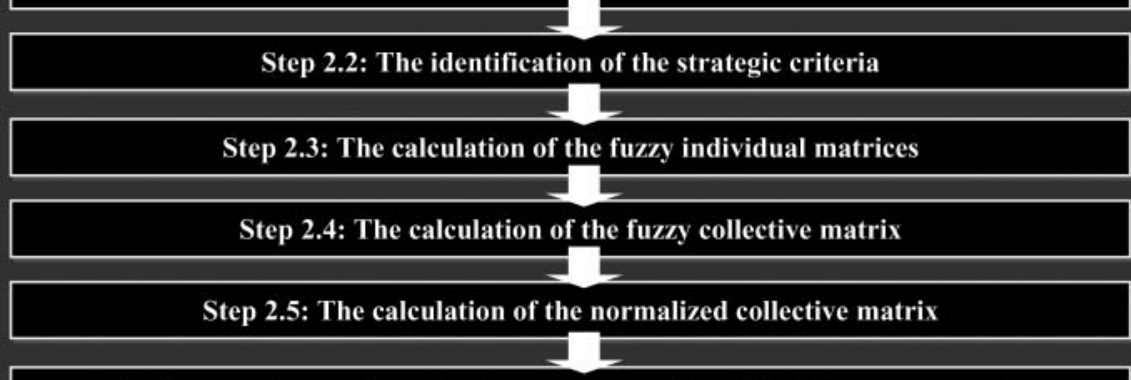

Step 2.6: The determination of the collective preference ranking of the ITS architecture subsystems

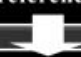

Step 2.6.1: The identification of the ideal and nadir ITS architecture subsystems

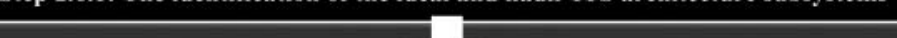

Step 2.6.2: The calculation of the normalized relative closeness vector

Phase 3: The calculation of the fuzzy real option values of the ITS architecture subsystems

Step 3.1: The construction of the individual fuzzy real option matrices

Step 3.2: The calculation of the fuzzy weighted collective real option matrix

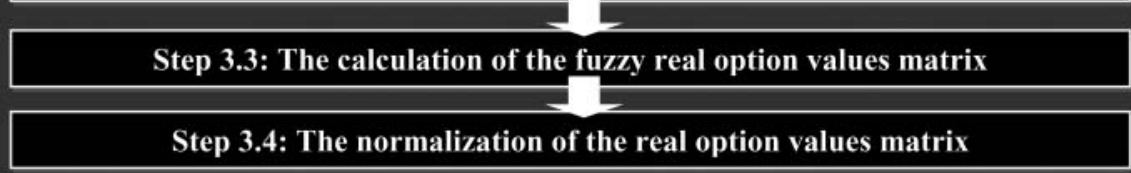

Phase 4: The determination of the optimal investment schedule for the ITS architecture subsystems

Figure 2 The proposed framework.

The optimal deferral time of the ITS architecture subsystem investments defined as the time period between the minimum deferral time and the maximum deferral time of the ITS investments will be found by solving model (P) in Phase 4 of our framework.

\section{Step 2.2: The Identification of the Strategic Criteria}

In this step, the board identifies a set of $x_{1}, x_{2}, \ldots, x_{p}$ investment risk criteria in the ITS architecture for the TOPSIS method.

\section{Step 2.3: The Calculation of the Fuzzy Individual Matrices}

In this step, we calculate the following fuzzy individual matrices $\left(\tilde{A}^{K}\right)$ and form the individual ordering of the ITS architecture subsystems. These preferences are reflected by assigning fuzzy numbers $n, n-1, n-2, \ldots 1$ to the negative criteria and fuzzy numbers $1,2,3, \ldots n$ to the positive criteria by each
ITS investment board member:

$$
\tilde{A}^{k}=\begin{gathered}
x_{1} \\
s_{1} \\
\vdots \\
s_{n}
\end{gathered}\left[\begin{array}{cccc}
\tilde{a}_{11}^{k} & \tilde{a}_{12}^{k} & \cdots & \tilde{a}_{1 p}^{k} \\
\tilde{a}_{21}^{k} & \tilde{a}_{22}^{k} & \cdots & \tilde{a}_{2 p}^{k} \\
\vdots & \vdots & \cdots & \vdots \\
\tilde{a}_{n 1}^{k} & \tilde{a}_{n 2}^{k} & \cdots & \tilde{a}_{n p}^{k}
\end{array}\right]
$$

Let $\tilde{a}_{i j}$ be the following trapezoidal fuzzy numbers:

$$
\tilde{a}_{i j}^{k}=\left(\left(a_{i j}^{k}\right)^{o},\left(a_{i j}^{k}\right)^{\alpha},\left(a_{i j}^{k}\right)^{\beta},\left(a_{i j}^{k}\right)^{\gamma}\right)
$$


Next, we substitute Equation (3) into Matrix (2) and rewrite the fuzzy individual matrices as follows:

$$
\tilde{A}^{k}=s_{2}\left[\begin{array}{ccccc}
x_{1} & x_{2} & \cdots & x_{p} \\
& s_{1}\left[\left(a_{11}^{k}\right)^{o},\left(a_{11}^{k}\right)^{\alpha},\left(a_{11}^{k}\right)^{\beta},\left(a_{11}^{k}\right)^{\gamma}\right) & \left(\left(a_{12}^{k}\right)^{o},\left(a_{12}^{k}\right)^{\alpha},\left(a_{12}^{k}\right)^{\beta},\left(a_{12}^{k}\right)^{\gamma}\right) & \ldots & \left(\left(a_{1 p}^{k}\right)^{o},\left(a_{1 p}^{k}\right)^{\alpha},\left(a_{1 p}^{k}\right)^{\beta},\left(a_{1 p}^{k}\right)^{\gamma}\right) \\
\left(\left(a_{21}^{k}\right)^{o},\left(a_{21}^{k}\right)^{\alpha},\left(a_{21}^{k}\right)^{\beta},\left(a_{21}^{k}\right)^{\gamma}\right) & \left(\left(a_{22}^{k}\right)^{o},\left(a_{22}^{k}\right)^{\alpha},\left(a_{22}^{k}\right)^{\beta},\left(a_{22}^{k}\right)^{\gamma}\right) & \ldots & \left(\left(a_{2 p}^{k}\right)^{o},\left(a_{2 p}^{k}\right)^{\alpha},\left(a_{2 p}^{k}\right)^{\beta},\left(a_{2 p}^{k}\right)^{\gamma}\right) \\
\vdots & \vdots & \ldots & \vdots \\
\left(\left(a_{n 1}^{k}\right)^{o},\left(a_{n 1}^{k}\right)^{\alpha},\left(a_{n 1}^{k}\right)^{\beta},\left(a_{n 1}^{k}\right)^{\gamma}\right) & \left(\left(a_{n 2}^{k}\right)^{o},\left(a_{n 2}^{k}\right)^{\alpha},\left(a_{n 2}^{k}\right)^{\beta},\left(a_{n 2}^{k}\right)^{\gamma}\right) & \ldots & \left(\left(a_{n p}^{k}\right)^{o},\left(a_{n p}^{k}\right)^{\alpha},\left(a_{n p}^{k}\right)^{\beta},\left(a_{n p}^{k}\right)^{\gamma}\right)
\end{array}\right]
$$

\section{Step 2.4: The Calculation of the Fuzzy Collective Matrix}

In this step, the fuzzy individual matrices $\left(\tilde{A}^{K}\right)$ constructed in Step 2.3 are used to form the following weighted fuzzy collective matrix $(\tilde{A})$ reflecting a collective ordering of the individual preferences for the ITS architecture subsystems:

$$
\tilde{A}=s_{2}\left[\begin{array}{cccc}
x_{1} & x_{2} \cdots & x_{p} & \\
\vdots & s_{n}
\end{array}\left[\begin{array}{cccc}
\tilde{a}_{11} & \tilde{a}_{12} & \cdots & \tilde{a}_{1 p} \\
\tilde{a}_{21} & \tilde{a}_{22} & \cdots & \tilde{a}_{2 p} \\
\vdots & \vdots & \ldots & \vdots \\
\tilde{a}_{n 1} & \tilde{a}_{n 2} & \cdots & \tilde{a}_{n p}
\end{array}\right]\right.
$$

Or:

$$
\begin{aligned}
& \begin{array}{llll}
x_{1} & x_{2} & \cdots & x_{p}
\end{array} \\
& \tilde{A}=\begin{array}{c}
s_{2} \\
s_{1} \\
s_{n}
\end{array}\left[\begin{array}{ccccc}
\left(\left(a_{11}\right)^{o},\left(a_{11}\right)^{\alpha},\left(a_{11}\right)^{\beta},\left(a_{11}\right)^{\gamma}\right) & \left(\left(a_{12}\right)^{o},\left(a_{12}\right)^{\alpha},\left(a_{12}\right)^{\beta},\left(a_{12}\right)^{\gamma}\right) & \ldots & \left(\left(a_{1 p}\right)^{o},\left(a_{1 p}\right)^{\alpha},\left(a_{1 p}\right)^{\beta},\left(a_{1 p}\right)^{\gamma}\right) \\
\vdots & \left.\left(a_{21}\right)^{o},\left(a_{21}\right)^{\alpha},\left(a_{21}\right)^{\beta},\left(a_{21}\right)^{\gamma}\right) & \left(\left(a_{22}\right)^{o},\left(a_{22}\right)^{\alpha},\left(a_{22}\right)^{\beta},\left(a_{22}\right)^{\gamma}\right) & \ldots & \left(\left(a_{2 p}\right)^{o},\left(a_{2 p}\right)^{\alpha},\left(a_{2 p}\right)^{\beta},\left(a_{2 p}\right)^{\gamma}\right) \\
\left(\left(a_{n 1}\right)^{o},\left(a_{n 1}\right)^{\alpha},\left(a_{n 1}\right)^{\beta},\left(a_{n 1}\right)^{\gamma}\right) & \left(\left(a_{n 2}\right)^{o},\left(a_{n 2}\right)^{\alpha},\left(a_{n 2}\right)^{\beta},\left(a_{n 2}\right)^{\gamma}\right) & \ldots & \left(\left(a_{n p}\right)^{o},\left(a_{n p}\right)^{\alpha},\left(a_{n p}\right)^{\beta},\left(a_{n p}\right)^{\gamma}\right)
\end{array}\right]
\end{aligned}
$$

where:

$$
\tilde{a}_{i j}=\frac{\sum_{k=1}^{l}\left(w(D M)_{k}\right) \tilde{a}_{i j}^{k}}{\sum_{k=1}^{l} w(D M)_{k}}
$$

\section{Step 2.5: The Calculation of the Normalized Collective Matrix}

In this step, each column vector of the collective Matrix (6) is divided by its norm: 


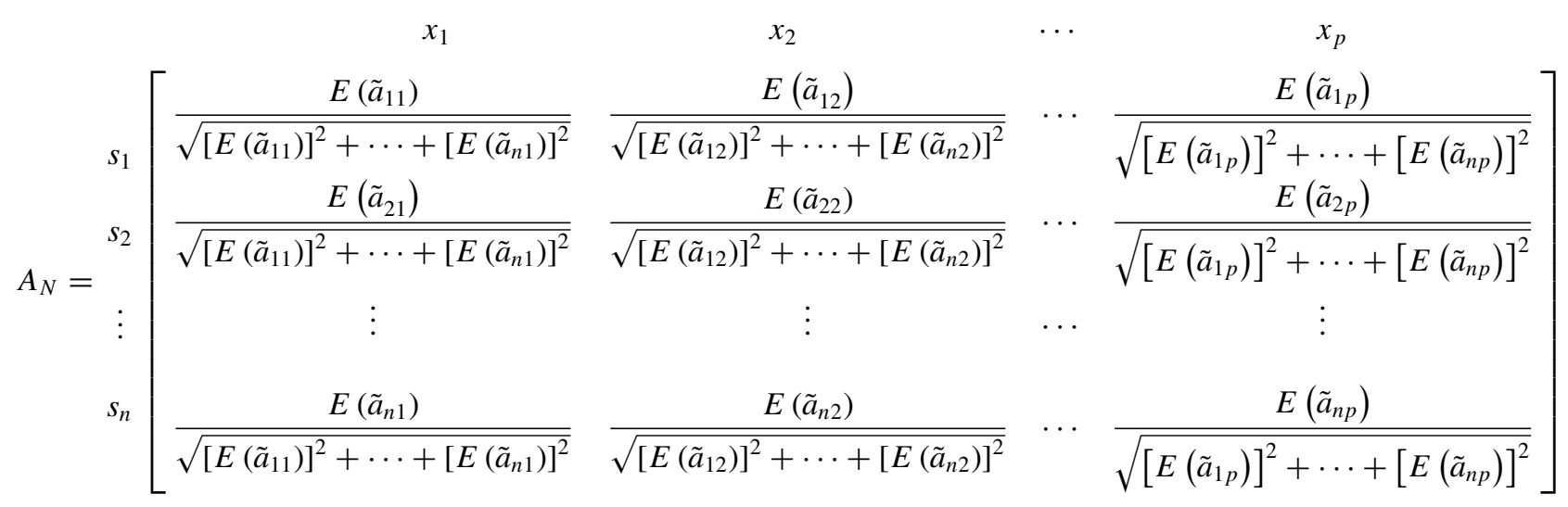

Step 2.6: The Determination of the Collective Preference Ranking of the ITS Architecture Subsystems

In this step, the group TOPSIS method is used to determine the collective preference ranking of the ITS architecture subsystems:

\section{Step 2.6.1: The Identification of the Ideal and Nadir ITS Architecture Subsystems}

In this step, the ideal and the nadir ITS Architecture subsystems, two sets, $S^{*}$ and $S^{-}$, are identified as follows:

$$
\begin{aligned}
& s^{*}=\left\{\left(\max _{i} c_{i j} / j \in J\right),\left(\min _{i} c_{i j} / j \in J^{\prime}\right)\right\}=\left\{s_{1}^{*}, \ldots, s_{j}^{*}, \ldots s_{p}^{*}\right\}(i=1,2, \ldots, n) \\
& s^{-}=\left\{\left(\min _{i} c_{i j} / j \in J\right),\left(\max _{i} c_{i j} / j \in J^{\prime}\right)\right\}=\left\{s_{1}^{-}, \ldots, s_{j}^{-}, \ldots s_{p}^{-}\right\}(i=1,2, \ldots, n)
\end{aligned}
$$

where:

$$
\begin{aligned}
c_{i j} & =\frac{E\left(\tilde{a}_{i j}\right)}{\sqrt{\left[E\left(\tilde{a}_{1 j}\right)\right]^{2}+\cdots+\left[E\left(\tilde{a}_{n j}\right)\right]^{2}}} \\
J & =\{j=1,2, \ldots, p / j \text { associated with positive criteria }\}
\end{aligned}
$$

and

$$
J^{\prime}=\{j=1,2, \ldots, p / j \text { associated with negative criteria }\}
$$

\section{Step 2.6.2: The Calculation of the Normalized Relative Closeness Vector}

In this step, the normalized relative closeness vector of the ITS architecture subsystem is defined as follows:

$$
\underline{V}_{R}=s_{2}\left[\begin{array}{c}
\frac{G_{1}}{\sqrt{\left(G_{1}\right)^{2}+\cdots+\left(G_{n}\right)^{2}}} \\
\vdots \\
s_{n}
\end{array}\left[\begin{array}{c}
\frac{G_{2}}{\sqrt{\left(G_{1}\right)^{2}+\cdots+\left(G_{n}\right)^{2}}} \\
\vdots \\
\frac{G_{n}}{\sqrt{\left(G_{1}\right)^{2}+\cdots+\left(G_{n}\right)^{2}}}
\end{array}\right]\right.
$$


where:

$$
\begin{gathered}
G_{i}=\frac{d_{i}^{-}}{d_{i}^{*}+d_{i}^{-}} \\
d_{i}^{*}=\sqrt{\sum_{j=1}^{p} w_{j}\left(c_{i j}-c_{j}^{*}\right)^{2}}(i=1,2, \ldots, n) \\
d_{i}^{-}=\sqrt{\sum_{j=1}^{p} w_{j}\left(c_{i j}-c_{j}^{-}\right)^{2}}(i=1,2, \ldots, n)
\end{gathered}
$$

\section{Phase 3: The Calculation of the Fuzzy Real Option Values of the ITS Architecture Subsystems}

In this phase, the real options equations suggested by Dos Santos (1994) are used to calculate the fuzzy real option values of the ITS architecture subsystems. Using the Dos Santos (1994) equations, we calculate the real option value of the $i$ th ITS subsystem at time $T_{j}$ on the basis of its expected cash flow-cost ratio $\left(\frac{B_{i}\left(T_{j}\right)}{C_{i}\left(T_{j}\right)}\right)$. The expected cash flow-cost consideration allows for the simultaneous consideration of the future expected benefits and future expected costs associated with each ITS subsystem. This phase is divided into the following four steps:

\section{Step 3.1: The Construction of the Individual Fuzzy Real Option Matrices}

Consider the following individual real option matrices given by each ITS investment board member:

$$
\begin{aligned}
& \tilde{B}\left(T_{1}\right) \quad \tilde{B}\left(T_{2}\right) \quad \ldots \quad \tilde{B}\left(T_{m}\right) \quad \tilde{C}\left(T_{1}\right) \quad \tilde{C}\left(T_{2}\right) \quad \ldots \quad \tilde{C}\left(T_{m}\right)
\end{aligned}
$$

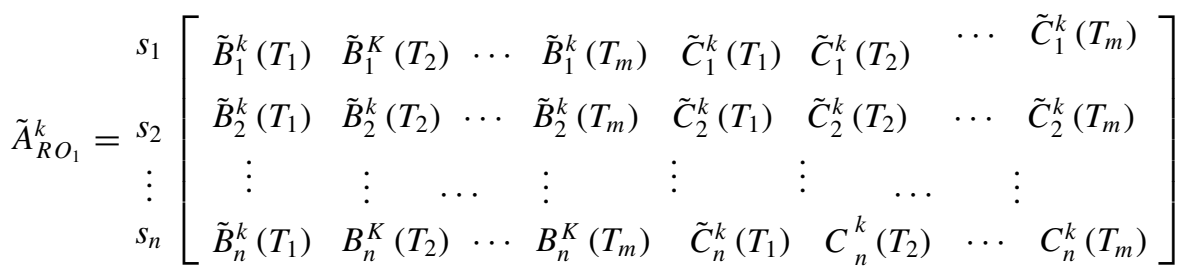

$$
\begin{aligned}
& (k=1,2, \ldots, l)
\end{aligned}
$$

Next, we use the following trapezoidal fuzzy numbers to calculate the individual fuzzy present values for the expected cash flows and costs associated with the $i$ th subsystem at time $T_{j}$ by the ITS investment board member $(\text { ITSIB })_{k}$ :

$$
\begin{gathered}
\tilde{B}_{i}^{k}\left(T_{j}\right)=\left(\left(B_{i}^{k}\left(T_{j}\right)\right)^{o},\left(B_{i}^{k}\left(T_{j}\right)\right)^{\alpha},\left(B_{i}^{k}\left(T_{j}\right)\right)^{\beta},\left(B_{i}^{k}\left(T_{j}\right)\right)^{\gamma}\right) \\
\tilde{C}_{i}^{k}=\left(\left(C_{i}^{k}\left(T_{j}\right)\right)^{o},\left(C_{i}^{k}\left(T_{j}\right)\right)^{\alpha},\left(C_{i}^{k}\left(T_{j}\right)\right)^{\beta},\left(C_{i}^{k}\left(T_{j}\right)\right)^{\gamma}\right) \\
(j=1,2, \ldots, m)
\end{gathered}
$$

We use the following intervals

$\left.\left(B_{i}^{k}\left(T_{j}\right)\right)^{o},\left(B_{i}^{k}\left(T_{j}\right)\right)^{\alpha}\right]: \quad$ The most possible values of the expected cash flows of the $i$ th subsystem at time $T_{j}$ evaluated by the ITS investment board member $(I T S I B)_{k}$

$\left(\left(B_{i}^{k}\left(T_{j}\right)\right)^{o}+\left(B_{i}^{k}\left(T_{j}\right)\right)^{\gamma}\right): \quad$ The upward potential for the expected cash flows of the $i$ th subsystem at time $T_{j}$ evaluated by the ITS investment board member $(\text { ITSIB })_{k}$

$\left(\left(B_{i}^{k}\left(T_{j}\right)\right)^{o}-\left(B_{i}^{k}\left(T_{j}\right)\right)^{\beta}\right): \quad$ The downward potential for the expected cash flows of the $i$ th subsystem at time $T_{j}$ evaluated by the ITS investment board member $(I T S I B)_{k}$ 
$\left[\left(C_{i}^{k}\left(T_{j}\right)\right)^{o},\left(C_{i}^{k}\left(T_{j}\right)\right)^{\alpha}\right]: \quad$ The most possible values of the expected cost of the $i$ th subsystem at time $T_{j}$ evaluated by the ITS investment board member $(I T S I B)_{k}$

$\left(\left(C_{i}^{k}\left(T_{j}\right)\right)^{o}+\left(C_{i}^{k}\left(T_{j}\right)\right)^{\gamma}\right):$ The upward potential for the expected cost of the $i$ th subsystem at time $T_{j}$ evaluated by the ITS investment board member $(I T S I B)_{k}$

$\left(\left(C_{i}^{k}\left(T_{j}\right)\right)^{o}-\left(C_{i}^{k}\left(T_{j}\right)\right)^{\beta}\right): \quad$ The downward potential for the expected cash flows of the $i$ th subsystem at time $T_{j}$ evaluated by the ITS investment board member $(I T S I B)_{k}$

Next, we rewrite the individual real option matrices by substituting Equation (18) into Matrix (17) as follows:

$$
\begin{aligned}
& \tilde{B}\left(T_{i}\right) \quad \tilde{C}\left(T_{i}\right) \\
& \left.\tilde{A}_{R O_{1}}^{k}\left(T_{i}\right)=s_{2}\left[\begin{array}{c}
\left(\left(B_{1}^{k}\left(T_{i}\right)\right)^{o},\left(B_{1}^{k}\left(T_{i}\right)\right)^{\alpha},\left(B_{1}^{k}\left(T_{i}\right)\right)^{\beta},\left(B_{1}^{k}\left(T_{i}\right)\right)^{\gamma}\right)\left(\left(C_{1}^{k}\left(T_{i}\right)\right)^{o},\left(C_{1}^{k}\left(T_{i}\right)\right)^{\alpha},\left(C_{1}^{k}\left(T_{i}\right)\right)^{\beta},\left(C_{1}^{k}\left(T_{i}\right)\right)^{\gamma}\right) \\
\left(\left(B_{2}^{k}\left(T_{i}\right)\right)^{o},\left(B_{2}^{k}\left(T_{i}\right)\right)^{\alpha},\left(B_{2}^{k}\left(T_{i}\right)\right)^{\beta},\left(B_{2}^{k}\left(T_{i}\right)\right)^{\gamma}\right)\left(\left(C_{2}^{k}\left(T_{i}\right)\right)^{o},\left(C_{2}^{k}\left(T_{i}\right)\right)^{\alpha},\left(C_{2}^{k}\left(T_{i}\right)\right)^{\beta},\left(C_{2}^{k}\left(T_{i}\right)\right)^{\gamma}\right) \\
\vdots \\
s_{n}
\end{array}\right] \begin{array}{c}
\vdots \\
\left(\left(B_{n}^{k}\left(T_{i}\right)\right)^{o},\left(B_{n}^{k}\left(T_{i}\right)\right)^{\alpha},\left(B_{n}^{k}\left(T_{i}\right)\right)^{\beta},\left(B_{n}^{k}\left(T_{i}\right)\right)^{\gamma}\right)\left(\left(C_{n}^{k}\left(T_{i}\right)\right)^{o},\left(C_{n}^{k}\left(T_{i}\right)\right)^{\alpha},\left(C_{n}^{k}\left(T_{i}\right)\right)^{\beta},\left(C_{n}^{k}\left(T_{i}\right)\right)^{\gamma}\right)
\end{array}\right]
\end{aligned}
$$

\section{Step 3.2: The Calculation of the Fuzzy Weighted Collective Real Option Matrix}

In this study, an argument can be made that the board members' judgments may deserve to be weighted differentially depending on their expertise. Otherwise, the judgments of the board's best members may be undervalued. A number of methods are suggested in the MCDA literature for assessing importance weights. These methods range from relatively simple ones, like the commonly used direct rating and point allocation methods to somewhat more advanced procedures, such as pairwise comparison, Delphi, SMART, or SWING methods (Salo, 1995). Although weight elicitation has been an area of concern in MCDA for some time, there are still no preferred methods (Riabacke, Danielson, Ekenberg, and Larsson, 2009).

Therefore, to form a fuzzy weighted collective real option matrix, the individual fuzzy real option matrices will be aggregated by the voting powers as follows:

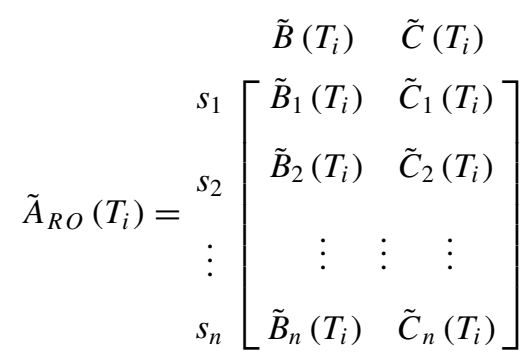

where:

$$
\begin{aligned}
& \tilde{B}_{i}\left(T_{i}\right)=\frac{\sum_{k=1}^{l}\left(w(D M)_{k}\right)\left(\tilde{B}_{i}^{k}\left(T_{i}\right)\right)}{\sum_{k=1}^{l} w(D M)_{k}} \\
& \tilde{C}_{i}\left(T_{i}\right)=\frac{\sum_{k=1}^{l}\left(w(D M)_{k}\right)\left(\tilde{C}_{i}^{k}\left(T_{i}\right)\right)}{\sum_{k=1}^{l} w(D M)_{k}}
\end{aligned}
$$


Step 3.3: The Calculation of the Fuzzy Real Option Values Matrix

In this step, we determine the real option values of the ITS subsystems at times $T_{1}, T_{2}, \ldots, T_{m}$ by the following fuzzy real option value matrix:

$$
\begin{aligned}
& \begin{array}{cccc}
T_{1} & T_{2} & \cdots & T_{m}
\end{array}
\end{aligned}
$$

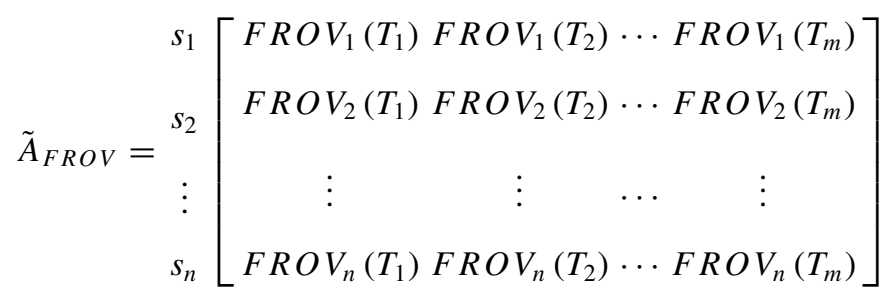

or:

$$
\tilde{A}_{F R O V}\left(T_{i}\right)=s_{2}\left[\begin{array}{c}
s_{1} \\
s_{n}
\end{array}\left[\begin{array}{c}
\tilde{B}_{1}\left(T_{i}\right) \cdot e^{-\delta T_{i}} \cdot N\left(D_{11}\left(T_{i}\right)\right)-\tilde{C}_{1}\left(T_{i}\right) \cdot e^{-r T_{i}} \cdot N\left(D_{21}\left(T_{i}\right)\right) \\
\tilde{B}_{2}\left(T_{i}\right) \cdot e^{-\delta T_{i}} \cdot N\left(D_{12}\left(T_{i}\right)\right)-\tilde{C}_{2}\left(T_{i}\right) \cdot e^{-r T_{i}} \cdot N\left(D_{22}\left(T_{i}\right)\right) \\
\vdots \\
\tilde{B}_{n}\left(T_{i}\right) \cdot e^{-\delta T_{i}} \cdot N\left(D_{1 n}\left(T_{i}\right)\right)-\tilde{C}_{n}\left(T_{i}\right) \cdot e^{-r T_{i}} \cdot N\left(D_{2 n}\left(T_{i}\right)\right)
\end{array}\right]=\left[\begin{array}{c}
F R O V_{1}\left(T_{i}\right) \\
F R O V_{2}\left(T_{i}\right) \\
\vdots \\
F R O V_{n}\left(T_{i}\right)
\end{array}\right]\right.
$$

where the $i$ th ITS subsystem cumulative normal probability distribution for $D_{1}$ and $D_{2}$ are as follows:

$$
\begin{aligned}
& N\left(D_{1}\left(T_{i}\right)\right) \quad N\left(D_{2}\left(T_{i}\right)\right) \\
& A_{R O_{3}}\left(T_{i}\right)=\begin{array}{c}
s_{1} \\
s_{2}
\end{array}\left[\begin{array}{cc}
N\left(D_{11}\left(T_{i}\right)\right) & N\left(D_{21}\left(T_{i}\right)\right) \\
N\left(D_{12}\left(T_{i}\right)\right) & N\left(D_{22}\left(T_{i}\right)\right) \\
s_{n}
\end{array}\right] \\
& D_{1}\left(T_{i}\right) D_{2}\left(T_{i}\right) \\
& A_{R O_{4}}(T)=\begin{array}{c}
s_{1} \\
s_{2} \\
s_{n}
\end{array}\left[\begin{array}{cc}
D_{11}\left(T_{i}\right) & D_{21}\left(T_{i}\right) \\
D_{12}\left(T_{i}\right) & D_{22}\left(T_{i}\right) \\
\vdots & \vdots \\
D_{1 n}\left(T_{i}\right) & D_{2 n}\left(T_{i}\right)
\end{array}\right]
\end{aligned}
$$


or equivalently:

$$
\begin{aligned}
& \begin{array}{ll}
D_{1}\left(T_{i}\right) & D_{2}\left(T_{i}\right)
\end{array}
\end{aligned}
$$

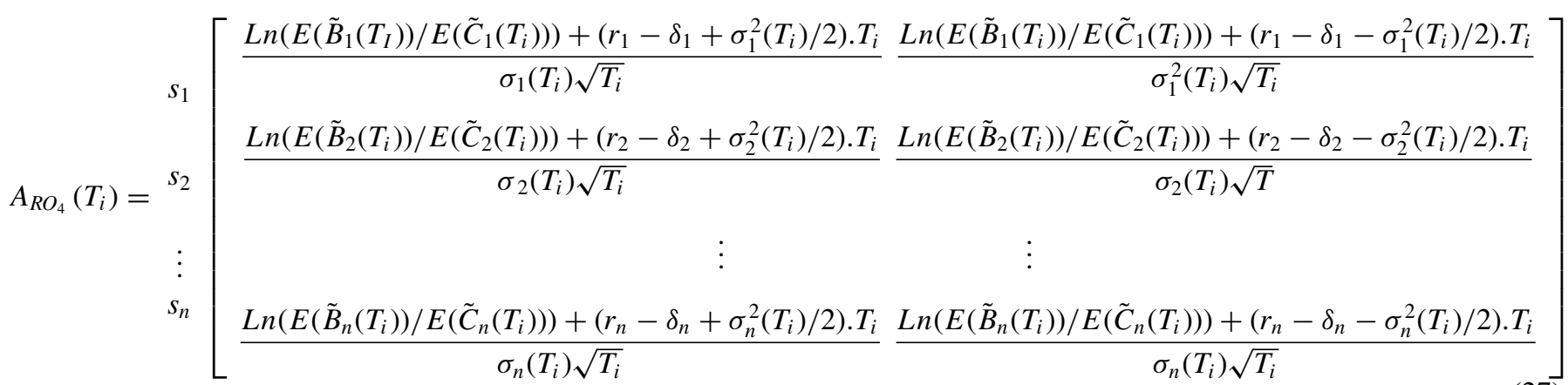

where, $E$ and $\sigma^{2}$ denote the possibilistic mean value and possibilistic variance operators as follows:

$$
A_{R O_{5}}\left(T_{i}\right)=\begin{array}{ccc}
E\left(\tilde{B}\left(T_{i}\right)\right) & E\left(\tilde{C}\left(T_{i}\right)\right) & \sigma^{2}\left(T_{i}\right) \\
s_{2} & \vdots \\
s_{n}
\end{array}\left[\begin{array}{ccc}
E\left(\tilde{B}_{1}\left(T_{i}\right)\right) & E\left(\tilde{C}_{1}\left(T_{i}\right)\right) & \sigma_{1}^{2}\left(T_{i}\right) \\
E\left(\tilde{B}_{2}\left(T_{i}\right)\right) & E\left(\tilde{C}_{2}\left(T_{i}\right)\right) & \sigma_{2}^{2}\left(T_{i}\right) \\
\vdots & \vdots & \vdots \\
E\left(\tilde{B}_{n}\left(T_{i}\right)\right) & E\left(\tilde{C}_{n}\left(T_{i}\right)\right) & \sigma_{n}^{2}\left(T_{i}\right)
\end{array}\right]
$$

Because $\tilde{B}_{i}$ and $\tilde{C}_{i}$ are the trapezoidal fuzzy numbers, we use the formulas proposed by Carlsson et al. (2007) to find the expected value and the variance of $\tilde{B}_{i}$ as follows:

$$
\begin{aligned}
& E\left(\tilde{B}_{i}\left(T_{j}\right)\right)=\frac{\left(B\left(T_{j}\right)\right)^{o}+\left(B\left(T_{j}\right)\right)^{\alpha}}{2}+\frac{\left(B\left(T_{j}\right)\right)^{\gamma}-\left(B\left(T_{j}\right)\right)^{\beta}}{6} \\
& E\left(\tilde{C}_{i}\left(T_{j}\right)\right)=\frac{\left(C\left(T_{j}\right)\right)^{o}+\left(C\left(T_{j}\right)\right)^{\alpha}}{2}+\frac{\left(C\left(T_{j}\right)\right)^{\gamma}-\left(C\left(T_{j}\right)\right)^{\beta}}{6} \\
& \sigma_{i}^{2}\left(T_{j}\right)=\frac{\left(\left(B\left(T_{j}\right)\right)^{\alpha}-\left(B\left(T_{j}\right)\right)^{o}\right)^{2}}{4}+\frac{\left(\left(B\left(T_{j}\right)\right)^{\alpha}-\left(B\left(T_{j}\right)\right)^{o}\right)\left(\left(B\left(T_{j}\right)\right)^{\beta}+\left(B\left(T_{j}\right)\right)^{\gamma}\right)}{6}+\frac{\left(\left(B\left(T_{j}\right)\right)^{\beta}+\left(B\left(T_{j}\right)\right)^{\gamma}\right)^{2}}{24}
\end{aligned}
$$

\section{Step 3.4: The Normalization of the Real Option Values Matrix}

In this step, each column vector of the real option values matrix is divided by its Euclidean norm $\left(\sqrt{\left[E\left(F R O V_{1}\left(T_{m}\right)\right)\right]^{2}+\cdots+\left[E\left(F R O V_{n}\left(T_{m}\right)\right)\right]^{2}}\right)$ which expresses the 'length' of each vector. This normalization is necessary to unify the scales of various objective dimensions in model $(\mathrm{P})$ proposed in Phase 4 of our framework:

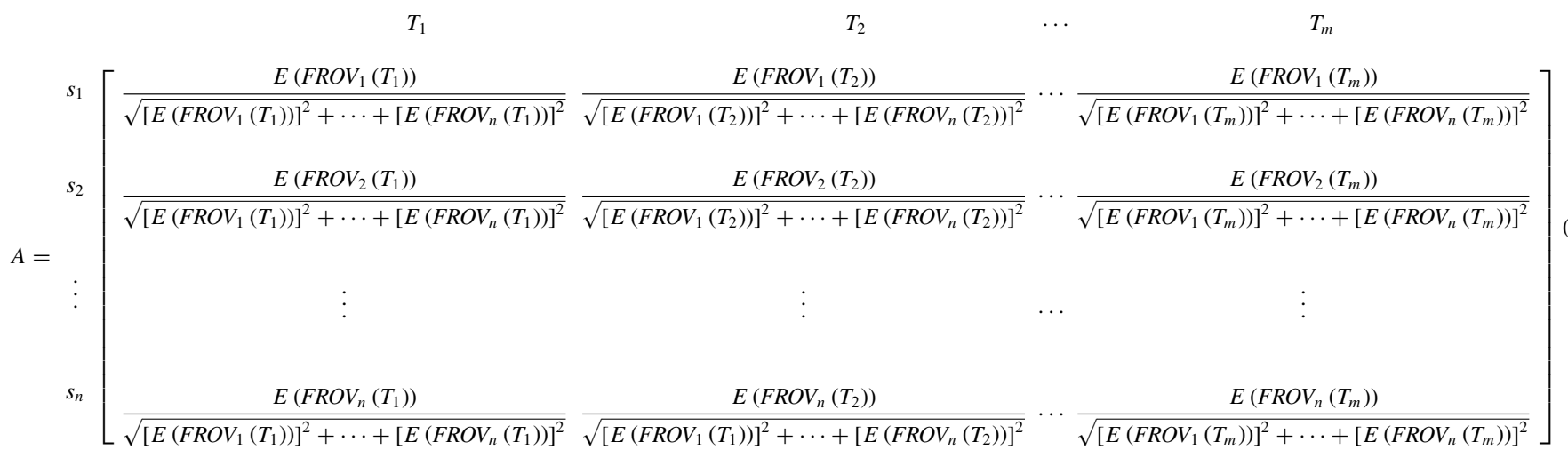


Phase 4: The Determination of the Optimal Investment Schedule for the ITS Architecture Systems

In this phase, we determine the optimal investment schedule for the $n$ ITS architecture subsystems based on the fuzzy risk values and the fuzzy real option values obtained in Phases 2 and 3. The risk and option values are considered as the coefficients of the objective functions in the following proposed group multi-objective decision-making model with a series of applicable constraints such as resource availability or the precedence relationship among the subsystems.

$$
\begin{aligned}
\operatorname{Max} & Z_{1} \\
= & \frac{G_{1}}{\sqrt{\left(G_{1}\right)^{2}+\cdots+\left(G_{n}\right)^{2}}} \cdot\left(y_{11}+y_{12}+\cdots+y_{1 m}\right) \\
& +\frac{G_{2}}{\sqrt{\left(G_{1}\right)^{2}+\cdots+\left(G_{n}\right)^{2}}} \cdot\left(y_{21}+y_{22}+\cdots+y_{2 m}\right) \\
& +\cdots \frac{G_{n}}{\sqrt{\left(G_{1}\right)^{2}+\cdots+\left(G_{n}\right)^{2}}} \cdot\left(y_{n 1}+y_{n 2}+\cdots+y_{n m}\right)
\end{aligned}
$$

$$
\begin{aligned}
\operatorname{Max} & Z_{2} \\
= & \frac{E\left[\operatorname{FROV}_{1}\left(T_{1}\right)\right]}{\sqrt{\left[E\left[\operatorname{FROV}_{1}\left(T_{1}\right)\right]\right]^{2}+\cdots+\left[E\left[\operatorname{FROV}_{n}\left(T_{1}\right)\right]\right]^{2}}} \cdot y_{11} \\
& +\frac{E\left[F R O V_{1}\left(T_{2}\right)\right]}{\sqrt{\left[E\left[F R O V_{1}\left(T_{2}\right)\right]\right]^{2}+\cdots+\left[E\left[F R O V_{n}\left(T_{2}\right)\right]\right]^{2}}} \cdot y_{12} \\
& +\cdots \frac{E\left[F R O V_{n}\right]\left(T_{m}\right)}{\sqrt{\left[E\left[F R O V_{1}\left(T_{m}\right)\right]\right]^{2}+\cdots\left[E\left[F R O V_{n}\left(T_{m}\right)\right]\right]^{2}}} \cdot y_{n m}
\end{aligned}
$$

Subject to: $($ Model $P$ )

$$
\begin{aligned}
& f_{1}\left(y_{11}, y_{12}, \ldots, y_{n m}\right) \leq 0 \\
& f_{2}\left(y_{11}, y_{12}, \ldots, y_{n m}\right) \leq 0 \\
& \vdots \\
& f_{r}\left(y_{11}, y_{12}, \ldots, y_{n m}\right) \leq 0 \\
& z_{1}+z_{2}+\cdots+z_{n}=1 \\
& z_{1}=y_{11}+y_{12}+\cdots+y_{1 m} \\
& z_{2}=y_{21}+y_{22}+\cdots+y_{2 m} \\
& z_{n}=y_{n 1}+y_{n 2}+\cdots+y_{n m} \\
& y_{i j}=0,1 \quad(i=1,2, \ldots, n), \quad(j=1,2, \ldots, m)
\end{aligned}
$$

where $f_{i}\left(y_{11}, y_{12}, \ldots, y_{n m}\right)$ is a given function of the $n$ ITS architecture subsystems.

The optimal solution for model $(F)$ is the optimal investment schedule of the ITS architecture subsystems. Next, we present a numerical example to demonstrate the applicability of the proposed framework and exhibit the efficacy of the procedures and algorithms.

\section{THE CASE STUDY}

Gotham City ${ }^{1}$ is planning to develop and implement a regional ${ }^{1}$ ITS architecture and needs to schedule an optimal investment strategy for the ITS subsystems. The method proposed in this study was used to assist Gotham City's Department of Transportation to evaluate and schedule a set of ITS architecture subsystems. Although the proposed framework was used to evaluate and schedule a set of ITS architecture subsystems at Gotham City, it could be modified and used to evaluate mixes of ITS investments. This is particularly essential for projects where different mixes could lead to different outcomes due to synergies among them. In those projects, each ITS investment mix could be evaluated independent from other competing investment mixes using the proposed framework. In addition, we can investigate the effect of scheduling different mixes of ITS architecture subsystems in model $(\mathrm{P})$ by performing sensitivity analysis with commercial optimization modeling software such as LINDO.

In Phase 1, the following four ITS investment board members were appointed by the Gotham City's Department of Transportation to participate in the planning process: $(I T I B)_{1},(I T I B)_{2},(I T I B)_{3}$ and $(I T I B)_{4}$

In Phase 2, we calculated the fuzzy risk values of the ITS architecture subsystems. Initially, the ITS investment board identified the following five ITS architecture subsystems presented

Table 1 The intelligent transportation system architecture classes and subsystems.

\begin{tabular}{ll}
\hline Class & \\
\hline Centers & Traffic Management \\
& Information Service Provider \\
& Emergency Management \\
& Emissions Management \\
& Toil Administration \\
& Transit Management \\
& Commercial Vehicle Administration \\
& Fleet and Freight Management \\
& Maintenance \& Construction Management \\
& Archived Data Management \\
& Remote Traveler Support \\
& Personal Information Access \\
& Vehicle \\
Travelers & Emergency Vehicle \\
& Commercial Vehicle \\
Vehicles & Transit Vehicle \\
& Maintenance \& Construction Vehicle \\
Roadway & Security Monitoring \\
Foll Collection \\
Parking Management \\
Commercial Vehicle Check \\
\end{tabular}

${ }^{1}$ We changed the name of the city to protect its anonymity and that of public service officials who participated in this research project. 
in Table 1 for implementation:

\section{$s_{1}:$ Traffic Management Subsystem (TMS) \\ $s_{2}:$ Emergency Management Subsystem (EM) \\ $s_{3}:$ Roadway Subsystem (RS) \\ $s_{4}:$ Personal Information Access Subsystem (PIAS) \\ $s_{5}:$ Toll Collection Subsystem (TCS)}

Table 2 presents a detailed description of each ITS architecture subsystem considered by the Gotham City's Department of Transportation.

In Step 2.2, the ITS investment board determined the following investment risk criteria to be considered in the evaluation of the five ITS architecture subsystems:

$x_{1}$ :User risk: The lack of user involvement during subsystem development; unfavorable attitudes of users towards a new subsystem.

$x_{2}$ :Complexity risk: Whether new technology is used; the complexity of the processes being automated; whether a large number of links to existing subsystems is required.

$x_{3}$ :Environment risk: Unanticipated changes in the ITS frameworks; obsolescence due to the introduction of new technology.

In Step 2.3, we used Equations (2) to (4) to determine four fuzzy individual matrices evaluated by the four ITS investment board members (see Tables 3-6).
In Step 2.4, we used Equations (5) to (7) to calculate the fuzzy collective matrix with regard to the importance weight vector $\left(w_{1}(D M), w_{2}(D M), w_{3}(D M), w_{4}(D M)\right)=$ $(0.25,0.25,0.25,0.25)$, given in Table 7.

In Step 2.5, we used Equation (8) to calculate the normalized collective matrix given in Table 8 .

In Step 2.6, we used Equations (9) to (16) to determine the normalized relative closeness vector with respect to the importance weight vector $\left(w_{1}, w_{2}, w_{3}\right)=(0.3,0.3,0.4)$ given in Table 9.

In Phase 3, we used Equations (17) to (30) to determine the normalized real options values of the five ITS architecture subsystems for Years 0, 1 and 2 presented in Table 10.

In Phase 4, we determined the optimal investment schedule for the five ITS architecture subsystems using the following two-objective decision-making model:

$$
\begin{aligned}
\text { Min } Z_{1}= & 0.62\left(y_{10}+y_{11}+y_{12}\right)+ \\
& 0.38\left(y_{20}+y_{21}+y_{22}\right)+ \\
& 0.32\left(y_{30}+y_{31}+y_{32}\right)+ \\
& 0.43\left(y_{40}+y_{41}+y_{42}\right)+ \\
& 0.42\left(x_{50}+x_{51}+x_{52}\right)
\end{aligned}
$$

\begin{tabular}{|c|c|}
\hline Subsystem & Description \\
\hline Traffic Management & $\begin{array}{l}\text { - Supports high occupancy vehicle lane management and coordination, road pricing, and other demand-management policies that can } \\
\text { alleviate congestion and influence mode selection } \\
\text { - Monitors and manages maintenance work and disseminates maintenance work schedules and road closures } \\
\text { - Manages reversible lane facilities and processes probe vehicle information } \\
\text { - Coordinates with rail operations to support safer and more efficient highway traffic management at highway-rail intersection } \\
\text { - Provides the capabilities to exercise control over those devices used for automated highway system traffic and vehicle control }\end{array}$ \\
\hline Emergency Management & $\begin{array}{l}\text { - Operates in various emergency centers supporting public safety including police and fire stations, search and rescue special } \\
\text { detachments, and HAZMAT response teams } \\
\text { - Creates, stores, and uses emergency response plans to facilitate coordinated response } \\
\text { - Tracks and manages emergency vehicle fleets using automated vehicle location technology and two-way communications with the } \\
\text { vehicle fleet }\end{array}$ \\
\hline Roadway & $\begin{array}{l}\text { - Includes equipment distributed on and along the roadway, which monitors and controls traffic } \\
\text { - Provides capability for emissions and environmental condition monitoring } \\
\text { - Supports automated vehicle safety systems in advanced implementations }\end{array}$ \\
\hline $\begin{array}{l}\text { Personal Information } \\
\text { Access }\end{array}$ & $\begin{array}{l}\text { - Enables travelers to receive formatted traffic advisories from home, place of work, major trip-generation sites, as well as over } \\
\text { personal portable devices and many electronic media; offering basic routing information and allowing users to select transportation } \\
\text { modes that avoid congestion, or more advanced capabilities enabling users to (a) specify transportation parameters unique to } \\
\text { individual needs and (b) receive travel information• Provides capabilities to receive route planning from infrastructure }\end{array}$ \\
\hline Toll Collection & $\begin{array}{l}\text { - Provides general payment administration capabilities and supports the electronic transfer of authenticated funds from customer to } \\
\text { transportation system operator } \\
\text { - Supports traveler enrollment and collection of pre-and postpayment transportation fees in coordination with the existing and } \\
\text { evolving financial infrastructure supporting electronic payment transactions } \\
\text { - Posts a transaction to the customer account and generates a bill (for postpayment accounts), debits an escrow account, or interfaces } \\
\text { to the financial infrastructure to debit a customer-designated account that supports communications with this subsystem to maintain } \\
\text { fee-collection operations }\end{array}$ \\
\hline
\end{tabular}

Table 2 Subsystems and descriptions of the intelligent transportation system.

Note. Source: U.S. Department of Transportation (2003). 
Table 3 The fuzzy individual matrix evaluated by the intelligent transportation system investment board member $(\text { ITSIB })_{1}$.

\begin{tabular}{lccccc}
\hline & $\begin{array}{c}\text { Traffic Management } \\
\text { Subsystem }\end{array}$ & $\begin{array}{c}\text { Emergency Management } \\
\text { Subsystem }\end{array}$ & Roadway Subsystem & $\begin{array}{c}\text { Personal Information } \\
\text { Access Subsystem }\end{array}$ & Toll Collection Subsystem \\
\hline User Risk & $(0.5,1.5,0.5,0.5)$ & $(1.5,2.5,0.5,0.5)$ & $(2.5,3.5,0.5,0.5)$ & $(0.5,1.5,0.5,0.5)$ & $(0.5,1.5,0.5,0.5)$ \\
Complexity Risk & $(2.5,3.5,0.5,0.5)$ & $(2.5,3.5,0.5,0.5)$ & $(1.5,2.5,0.5,0.5)$ & $(2.5,3.5,0.5,0.5)$ & $(1.5,2.5,0.5,0.5)$ \\
Market Risk & $(1.5,2.5,0.5,0.5)$ & $(0.5,1.5,0.5,0.5)$ & $(0.5,1.5,0.5,0.5)$ & $(0.5,1.5,0.5,0.5)$ & $(2.5,3.5,0.5,0.5)$ \\
\hline
\end{tabular}

Table 4 The fuzzy individual matrix evaluated by the intelligent transportation system investment board member $(I T S I B)_{2}$.

\begin{tabular}{lccccc}
\hline & $\begin{array}{c}\text { Traffic Management } \\
\text { Subsystem }\end{array}$ & $\begin{array}{c}\text { Emergency Management } \\
\text { Subsystem }\end{array}$ & Roadway Subsystem & $\begin{array}{c}\text { Personal Information } \\
\text { Access Subsystem }\end{array}$ & Toll Collection Subsystem \\
\hline User Risk & $(0.75,1.25,0.25,0.25)$ & $(0.75,1.25,0.25,0.25)$ & $(2.75,3.25,0.25,0.25)$ & $(0.75,1.25,0.25,0.25)$ & $(0.75,1.25,0.25,0.25)$ \\
Complexity Risk & $(1.75,2.25,0.25,0.25)$ & $(2.75,3.25,0.25,0.25)$ & $(0.75,1.25,0.25,0.25)$ & $(1.75,2.25,0.25,0.25)$ & $(2.75,3.25,0.25,0.25)$ \\
Market Risk & $(2.75,3.25,0.25,0.25)$ & $(1.75,2.25,0.25,0.25)$ & $(1.75,2.25,0.25,0.25)$ & $(2.75,3.25,0.25,0.25)$ & $(1.75,2.25,0.25,0.25)$ \\
\hline
\end{tabular}

Table 5 The fuzzy individual matrix evaluated by the intelligent transportation system investment board member $(I T S I B)_{3}$.

\begin{tabular}{lccccc}
\hline & $\begin{array}{c}\text { Traffic Management } \\
\text { Subsystem }\end{array}$ & $\begin{array}{c}\text { Emergency Management } \\
\text { Subsystem }\end{array}$ & Roadway Subsystem & $\begin{array}{c}\text { Personal Information } \\
\text { Access Subsystem }\end{array}$ & Toll Collection Subsystem \\
\hline User Risk & $(1.5,2.5,0.5,0.5)$ & $(0.5,1.5,0.5,0.5)$ & $(1.5,2.5,0.5,0.5)$ & $(0.5,1.5,0.5,0.5)$ & $(0.5,1.5,0.5,0.5)$ \\
Complexity Risk & $(2.5,3.5,0.5,0.5)$ & $(2.5,3.5,0.5,0.5)$ & $(2.5,3.5,0.5,0.5)$ & $(1.5,2.5,0.5,0.5)$ & $(2.5,3.5,0.5,0.5)$ \\
Market Risk & $(0.5,1.5,0.5,0.5)$ & $(1.5,2.5,0.5,0.5)$ & $(0.5,1.5,0.5,0.5)$ & $(2.5,3.5,0.5,0.5)$ & $(1.5,2.5,0.5,0.5)$ \\
\hline
\end{tabular}

Table 6 The fuzzy individual matrix evaluated by the intelligent transportation system investment board member $(I T S I B)_{4}$.

\begin{tabular}{lccccc}
\hline & $\begin{array}{c}\text { Traffic Management } \\
\text { Subsystem }\end{array}$ & $\begin{array}{c}\text { Emergency Management } \\
\text { Subsystem }\end{array}$ & Roadway Subsystem & $\begin{array}{c}\text { Personal Information } \\
\text { Access Subsystem }\end{array}$ & Toll Collection Subsystem \\
\hline User Risk & $(0.8,1.2,0.2,0.2)$ & $(1.8,2.2,0.2,0.2)$ & $(2.8,3.2,0.2,0.2)$ & $(0.8,1.2,0.2,0.2)$ & $(1.8,2.2,0.2,0.2)$ \\
Complexity Risk & $(2.8,3.2,0.2,0.2)$ & $(2.8,3.2,0.2,0.2)$ & $(1.8,2.2,0.2,0.2)$ & $(1.8,2.2,0.2,0.2)$ & $(2.8,3.2,0.2,0.2)$ \\
Market Risk & $(1.8,2.2,0.2,0.2)$ & $(0.8,1.2,0.2,0.2)$ & $(0.8,1.2,0.2,0.2)$ & $(2.8,3.2,0.2,0.2)$ & $(0.8,1.2,0.2,0.2)$ \\
\hline
\end{tabular}

Table 7 The fuzzy collective matrix.

\begin{tabular}{lccccc}
\hline & $\begin{array}{c}\text { Traffic Management } \\
\text { Subsystem }\end{array}$ & $\begin{array}{c}\text { Emergency Management } \\
\text { Subsystem }\end{array}$ & Roadway Subsystem & $\begin{array}{c}\text { Personal Information } \\
\text { Access Subsystem }\end{array}$ & $\begin{array}{c}\text { Toll Collection Subsystem } \\
\text { User Risk }\end{array}$ \\
Complexity Risk & $(0.89,1.61,0.36,0.36)$ & $(1.14,1.86,0.36,0.36)$ & $(2.39,3.11,0.36,0.36)$ & $(0.64,1.36,0.36,0.36)$ & $(0.89,1.61,0.36,0.36)$ \\
Market Risk & $(1.39,3.11,0.36,0.36)$ & $(2.64,3.36,0.36,0.36)$ & $(1.64,2.36,0.36,0.36)$ & $(1.89,2.61,0.36,0.36)$ & $(2.39,3.11,0.36,0.36)$ \\
\hline
\end{tabular}

Table 8 The normalized collective matrix.

\begin{tabular}{|c|c|c|c|c|c|}
\hline & $\begin{array}{c}\text { Traffic Management } \\
\text { Subsystem }\end{array}$ & $\begin{array}{c}\text { Emergency Management } \\
\text { Subsystem }\end{array}$ & Roadway Subsystem & $\begin{array}{l}\text { Personal Information } \\
\text { Access Subsystem }\end{array}$ & Toll Collection Subsystem \\
\hline User Risk & 0.125 & 0.150 & 0.275 & 0.100 & 0.125 \\
\hline Market Risk & 0.175 & 0.300 & 0.200 & 0.225 & 0.275 \\
\hline
\end{tabular}

Table 9 The normalized relative closeness vector.

\begin{tabular}{lccccc}
\hline & $\begin{array}{c}\text { Traffic Management } \\
\text { Subsystem }\end{array}$ & $\begin{array}{c}\text { Emergency Management } \\
\text { Subsystem }\end{array}$ & Roadway Subsystem & $\begin{array}{c}\text { Personal Information Access } \\
\text { Subsystem }\end{array}$ & Toll Collection Subsystem \\
\hline$\underline{V}_{R}$ & 0.62 & 0.38 & 0.32 & 0.43 & 0.42 \\
\hline
\end{tabular}


Table 10 The normalized real option values of the intelligent transportation system architecture subsystems.

\begin{tabular}{lccccc}
\hline Deferral Time & $\begin{array}{c}\text { Traffic Management } \\
\text { Subsystem }\end{array}$ & $\begin{array}{c}\text { Emergency Management } \\
\text { Subsystem }\end{array}$ & Roadway Subsystem & $\begin{array}{c}\text { Personal Information } \\
\text { Access Subsystem }\end{array}$ & Toll Collection Subsystem \\
\hline 0 & 0.230 & 0.250 & 0.200 & 0.150 & 0.170 \\
1 & 0.190 & 0.190 & 0.250 & 0.170 & 0.200 \\
2 & 0.210 & 0.150 & 0.230 & 0.210 & 0.190 \\
\hline
\end{tabular}

$\operatorname{Max} Z_{2}=0.23 y_{10}+0.19 y_{11}+0.21 y_{12}+$

$$
\begin{aligned}
& 0.25 y_{20}+0.19 y_{21}+0.15 y_{22}+ \\
& 0.2 y_{30}+0.25 y_{31}+0.23 y_{32}+ \\
& 0.15 y_{40}+0.17 y_{41}+0.21 y_{42}+ \\
& 0.17 y_{50}+0.2 y_{51}+0.19 y_{52}
\end{aligned}
$$

Subject to: $($ Model $P)$

$$
\begin{aligned}
& y_{10}+y_{11}+y_{12}=1 \\
& y_{20}+y_{21}+y_{22}=1 \\
& y_{30}+y_{31}+y_{32}=1 \\
& y_{40}+y_{41}+y_{42}=1 \\
& y_{50}+y_{51}+y_{52}=1
\end{aligned}
$$

$y_{10}, y_{11}, y_{12}, y_{20}, y_{21}, y_{22} \cdot y_{30}, y_{31}, y_{32}, y_{40}, y_{41}, y_{42}, y_{50}, y_{51}, y_{52}$

$$
=0,1
$$

The optimal solution for model $P$ given in Table 11 shows that the traffic management subsystem (TMS) and the toll collection subsystem (TCS) should be scheduled to start right away, and the roadway subsystem (RS), the emergency management subsystem (EM) and the personal information access subsystem (PIAS) should be scheduled to start in 2 years.

\section{DISCUSSION AND IMPLICATIONS}

It is hard to say for sure what ITS architecture is the best, but, we can make the ITS investment scheduling more comprehensive and systematic. The fuzzy group MCDA framework used at Gotham City was intended to enhance decision making. The four ITS investment board members were highly educated; three of them held graduate degrees in engineering and one of them held a master of business administration. To this end, a more logical and persuasive multi-criteria framework was necessary to gain their confidence and support. Although the board members were educated and creative, their managerial judgment and intuition were limited by their background and experience. Nevertheless, all four board members were seasoned transportation professionals with 18-34 years of experience in planning, design, construction, and operations of transportation systems, among many other fields. Each board member had a range of expertise including risk-benefit analysis, engineering management, financial management, and budgeting. Upon completion of the ITS investment scheduling, the board met to discuss the results and finalize its recommendations. The four board members unanimously agreed that the proposed framework provided invaluable analysis aids and information processing support. They were convinced that the result was unbiased and consistent with their goals and objectives.

Armed with this feedback, the board members were confident that they could sell their recommendation to the city, state and federal officials. Despite this confidence, they were all aware that building internal and external alliances was a difficult task. The board members agreed to target various stakeholders and key people in order to gain their support. They began building alliances with the city officials and the state and federal highway administration officials. This process involved fostering collaboration and avoiding alienation of potential allies.

The board was adamant about the importance of gaining support from the stakeholders. Gaining the support of various city, state and federal agencies was easier than it may seem from the outside. The board members had already built internal and exter-

\begin{tabular}{|c|c|c|c|c|c|}
\hline Deferral Time & $\begin{array}{l}\text { Traffic Management } \\
\text { Subsystem }\end{array}$ & $\begin{array}{c}\text { Emergency Management } \\
\text { Subsystem }\end{array}$ & Roadway Subsystem & $\begin{array}{l}\text { Personal Information } \\
\text { Access Subsystem }\end{array}$ & Toll Collection Subsystem \\
\hline 0 & $\sqrt{ }$ & - & - & - & $\sqrt{ }$ \\
\hline 1 & - & - & - & - & - \\
\hline 2 & - & $\sqrt{ }$ & $\sqrt{ }$ & $\sqrt{ }$ & - \\
\hline
\end{tabular}
nal alliances and support of various key people. They discussed the overwhelming support and the tangible and intangible benefits of the selected ITS framework with the key people who, in turn, agreed to support the proposed recommendation. The board was also charged to develop a long-term plan to measure the ITS success.

The analysis of this case study allows the articulation of a series of key factors that can be considered as important in

Table 11 The optimal solution for model $P$. 
contributing to successful ITS investment scheduling. The first element is getting the key people on board. The second factor is building internal and external alliances. The third key ingredient is the persistent and systematic processes in place to evaluate the ITS success.

\section{CONCLUSIONS AND FUTURE RESEARCH DIRECTIONS}

The increasing complexity in the transportation system and the larger number of conflicting criteria has made the ITS investment selection and planning a difficult and complex task. The traditional ITS investment selection methods overemphasize quantitative and economic analysis and often neglect to consider qualitative and non-economic data in the formal selection process. Furthermore, crisp data are fundamentally indispensable in traditional ITS investment selection methods. However, the data in real-world problems are often qualitative, imprecise and ambiguous. In this article, we proposed a novel fuzzy group multi-criteria framework for ITS investment evaluation and selection that takes into consideration (a) the qualitative and quantitative criteria and their respective value judgments, (b) the verbal expressions and linguistic variables for qualitative judgments that lead to ambiguity in the decision process, and (c) imprecise or vague judgments.

The proposed framework does not imply a higher-level of accuracy in ITS investment scheduling. Although the approach has an air of mathematical sophistication, a more logical and persuasive framework was necessary to gain the confidence and support of a group of highly educated decision makers and city planners. Nevertheless, the board members make a number of value judgments, which may impair the results. Therefore, the success of the framework is highly dependent on appointing the right board members with experience and wisdom.

Our framework helps the board members to think systematically about complex transportation planning problems in general, and planning for ITS in particular. We decompose the ITS framework evaluation problem into manageable steps and integrate the results to arrive at a solution consistent with the goals and objectives specified by the city, state, and federal stakeholders. This decomposition encourages board members to carefully consider uncertain conditions. The proposed structured framework does not imply a deterministic approach in transportation planning. Although our approach enables board members to assimilate the precise data and imprecise or ambiguous judgments into a formal systematic approach, it should be used with care and in conjunction with management experience. Managerial judgment is an integral component of the ITS investment scheduling; therefore, the effectiveness of the model relies heavily on the board members cognitive capabilities.

There are a number of challenges involved in the proposed research. These challenges provide a great deal of fruitful scope for future research. The analysis of real options enables man- agers and decision makers to estimate the value of system flexibility. Incorporating this capability into the ITS architecture enables managers to adjust the subsystem implementation as needed when new information becomes available.

\section{REFERENCES}

Belton, V., and Stewart, T. J. (2002). Multiple criteria decision analysis: An integrated approach. Boston, Massachusetts: Kluwer.

Benaroch, M., and Kauffman, R. J. (1999). A case for real options pricing analysis to evaluate information technology project investments, Information Systems Research, 10(1), 70-86.

Black, F., and Scholes, M. (1973). The pricing of options and corporate liabilities. The Journal of Political Economy, 81, 637-654.

Black, F., and Scholes, M. (1974). The effects of dividend yield and dividend policy on common stock prices and returns. Journal of Financial Economics, 1(1), 1-22.

Boyle, P. P. (1977). Options: A Monte Carlo approach. Journal of Financial Economics, 4, 323-338.

Bristow, A. L., Pearman, A. D., and Shires, J. D. (1997). An assessment of advanced transport telematics evaluation procedures. Transport Reviews, 17, 177-205.

Busby, J. S., and Pitts, C. G. C. (1997). Real options and capital investment decisions. Management Accounting, 75(10), 38-39.

Carlsson, C., and Fullér, R. (2003). A fuzzy approach to real option valuation. Fuzzy Sets and Systems, 139, 297-312.

Collan, M., Fullér, R., and Mezei, J. (2009). A fuzzy pay-off method for real option valuation. Journal of Applied Mathematics and Decision Sciences, 2009, 1-14.

Cox, J., Ross, S., and Rubinstein, M. (1979). Option pricing: A simplified approach. Journal of Financial Economics, 7, 229-263.

Crainic, T. G., Gendreau, M., and Potvin, J. Y. (2009). Intelligent freight-transportation systems: Assessment and the contribution of operations research. Transportation Research Part C: Emerging Technologies, 17, 541-557.

Datar, V., and Mathews, S. (2004). European real options: An intuitive algorithm for the Black Scholes formula. Journal of Applied Finance, 14(1), 45-51.

Datar, V., and Mathews, S. (2007). A practical method for valuing real options: The Boeing approach. Journal of Applied Corporate Finance, 19, 95-104.

De Brucker, K., Verbeke, A., and Macharis, C. (2004). The applicability of multicriteria analysis to the evaluation of intelligent transportation systems (ITS). Research in Transportation Economics, 8, 151179.

De Corla-Souza, P., Everett, J., Gardner, B., and Culp, M. (1997). Total cost analysis: An alternative to benefit-cost analysis in evaluating transportation alternatives. Transportation, 24, 107-123.

De Neufville, R. (2003). Real options: Dealing with uncertainty in systems planning and design. Integrated Assessment, 4(1), 26-34.

Dos Santos, B. L. (1994). Assessing the value of strategic information technology investments. London, England: Chapman \& Hall.

Drakopoulos, J. A. (1995). Probabilities, possibilities, and fuzzy sets. Fuzzy Sets and Systems, 75(1), 1-15.

Gillen, D., and Levinson, D. (2004). Assessing the investment in ITS: An introduction. In D. Gillen and D. Levinson (Eds.), Assessing the benefits and costs of ITS: Making the business case for ITS investments (pp. 1-16). Boston, MA: Kluwer. 
Haynes, K. E., and Li, M. (2004). Analytical alternatives in intelligent transportation system (ITS) evaluation. Research in Transportation Economics, 8, 127-149.

Hwang, C. L., and Yoon, K. (1981). Multiple attribute decision making methods and applications. Berlin, Germany: Springer.

Hodota, K. (2006). $R \& D$ and deployment valuation of intelligent transportation systems: A case example of the intersection collision avoidance systems (Master's thesis). Massachusetts Institute of Technology, Cambridge, MA.

Iniestra, J. G., and Gutiérrez, J. G. (2009). Multicriteria decisions on interdependent infrastructure transportation projects using an evolutionary-based framework. Applied Soft Computing, 9, 512-526.

Kim, S. H., and Ahn, B. S. (1999). Interactive group decision making procedure under incomplete information. European Journal of Operational Research, 116, 498-507.

Kim, G., Park, C. S., and Yoon, K. P. (1997). Identifying investment opportunities for advanced manufacturing systems with comparativeintegrated performance measurement. International Journal of Production Economics, 50, 23-33.

Leviakangas, P. (1998, October). Some new aspects and ideas for economic evaluation of ITS investments. Paper presented at the 5th World Congress on Intelligent Transport Systems, Seoul, South Korea.

Leviakangas, P., and Lahesmaa, J. (2002). Profitability evaluation of intelligent transportation system investments. Journal of Transportation Engineering, 128, 276-286.

Levine, J., and Underwood, S. E. (1996). A multiattribute analysis of goals for intelligent transportation system planning. Transportation Research Part C: Emerging Technologies, 4, 97-111.

Ma, Y., Zhou, Y., Chowdhury, M., Wang, K.-C., and Fries, R. N. (2009). A framework for performance evaluation of communication alternatives for intelligent transportation systems. Journal of Intelligent Transportation Systems, 13, 111-126.

Macharis, C., Verbeke, A., and De Brucker, K. (2004). The strategic evaluation of new technologies through multicriteria analysis: The advisors case. Research in Transportation Economics, 8, 443-446.

Mathews, S., and Salmon, J. (2007). Business engineering: A practical approach to valuing high-risk, high-return projects using real options. In P. Gray (Ed.), Tutorials in operations research (pp. 157-175). Hanover, MD: INFORMS.

McConnell, J. (2005). Lecture notes from MIT 1.212: An introduction to intelligent transportation systems. Boston, Massachusetts: MIT Open Courseware.

McGrath, R. G. (1997). A real options logic for initiating technology positioning investments. Academy of Management Review, 22, 974-996.
Poyhonen, M. A., Hamalainen, R. P., and Salo, A. A. (1997). An experiment on the numerical modelling of verbal ratio statements. Journal of Multi-Criteria Decision Analysis, 6(1), 1-10.

Quek, C., Pasquier, M., and Lim, B. (2009). A novel self-organizing fuzzy rule-based system for modelling traffic flow behavior. Expert Systems With Applications, 36, 12167-12178.

Riabacke, M., Danielson, M., Ekenberg, L., and Larsson, A. (2009). A prescriptive approach for eliciting imprecise weight statements in an MCDA process. In F. Rossi and A. Tsoukias (Eds.), Algorithmic decision theory (pp. 168-179). Berlin, Germany: Springer-Verlag.

Salo, A. A. (1995). Interactive decision aiding for group decision support. European Journal of Operational Research, 84(1), 134149.

Scarso, E. (1996). Timing the adoption of a new technology: An optionbased approach. Management Decision, 34(3), 41-48.

Schniederjans, M. J., Hamaker, J. L., and Schniederjans, A. M. (2004). Information technology investment: Decision-making methodology. Singapore: World Scientific Organization.

Shaheen, S. A., and Finson, R. (2004). Intelligent transportation systems. In C. Cleveland (Eds.), Encyclopedia of energy (p. 487). Amsterdam, Netherlands: Elsevier.

Shih, H. S., Shyur, H. J., and Lee, E. S. (2007). An extension of TOPSIS for group decision making. Mathematical and Computer Modelling, 45, 801-813.

Sussman, J. M. (2005). Perspectives on intelligent transportation systems (ITS). New York, NY: Springer.

Thill, J. C., Rogova, G., and Yan, J. (2004). Evaluating benefits and costs of intelligent transportation systems elements from a planning perspective. Research in Transportation Economics, 8, 571-603.

U.S. Department of Transportation. (2009). National intelligent transportation system (ITS) architecture. Retrieved from http://www.standards.its.dot.gov/learn_NatITS.asp

Valls, A., and Torra, V. (2000). Using classification as an aggregation tool in MCDM. Fuzzy Sets and Systems, 15(1), 159-168.

Wang, J. G., Lin, C. J., and Chen, S. M. (2010). Applying fuzzy method to vision-based lane detection and departure warning system. Expert Systems With Applications, 37(1), 113-126.

Yang, J. B., and Xu, D. L. (2002). On the evidential reasoning algorithm for multiattribute decision analysis under uncertainty. IEEE Transactions on Systems, Man, and Cybernetics-Part A: Systems and Humans, 32, 289-304.

Zadeh, L. A. (1965). Fuzzy sets. Information and Control, 8, 338-353.

Zadeh, L. A. (1983). The role of fuzzy logic in the management of uncertainty in expert systems. Fuzzy Sets and Systems, 11, 197-198.

Zeleny, M. (1974). A concept of compromise solutions and the method of the displaced ideal. Computers and Operations Research, 1, 479-496. 